\title{
Fenton Oxidation Kinetics of Azo Dye Acid Light Yellow 2G Wastewater by Online Spectrophotometry
}

\author{
Aifang Gao*(**)†, Yiyun An*, Liuliu Ma*, Yingying Lian* and Aiguo Li* \\ *School of Water Resources and Environment, Hebei GEO University, Shijiazhuang 050031, China \\ **Hebei Province Collaborative Innovation Center for Sustainable Utilization of Water Resources and Optimization \\ of Industrial Structure, Hebei Province Key Laboratory of Sustained Utilization and Development of Water Resources, \\ Shijiazhuang 050031, China \\ †Corresponding author: 1lhx2006@126.com
}

Nat. Env. \& Poll. Tech. Website: www.neptjournal.com

Received: 03-02-2020

Revised: $28-02-2020$

Accepted: 02-05-2020

Key Words:

Online spectrophotometry

Fenton oxidation

Acid Light Yellow 2G
Reaction kinetics

\begin{abstract}
The online spectrophotometric technique was adopted to monitor the degradation of simulated Acid Light Yellow 2G (ALY 2G) solution with the Fenton oxidation process, and the kinetic process was also discussed. The effects of the initial concentration of $\mathrm{H}_{2} \mathrm{O}_{2}$ and $\mathrm{Fe}_{2} \mathrm{SO}_{4}, \mathrm{pH}$ value, and initial dye concentration on the degradation process were studied. The results showed that the ALY $2 \mathrm{G}$ can be degraded by Fenton oxidation, and the colour removal rate of Acid Light Yellow 2G was 94.66\% after $300 \mathrm{~s}$ when the concentration of simulated wastewater was $20 \mathrm{mg} / \mathrm{L}$, the dosage of $\mathrm{Fe}^{2+}$ was 0.1 $\mathrm{mmol} / \mathrm{L}$, the dosage of $\mathrm{H}_{2} \mathrm{O}_{2}$ was $0.6 \mathrm{mmol} / \mathrm{L}$, and the $\mathrm{pH}$ was 3 . The degradation process was divided into two stages: the first stage, the degradation rate is very fast; in the second stage, with the extension of reaction time, the increase of decolourization rate decreases. The first stage of the reaction accords with the first-order kinetics, and the reaction rate constant $\mathrm{K}_{\mathrm{ap}}$ is $0.04824 \mathrm{~s}^{-1}$. The intrinsic reaction rate constant of ALY $2 \mathrm{G}$ and hydroxyl in aqueous solution in the Fenton oxidation method is $0.55 \times$ $10^{9} \mathrm{M}^{-1} \mathrm{~s}^{-1}$.
\end{abstract}

\section{INTRODUCTION}

Textile and dyeing industries are one of the most important chemical industries. However, many printing and dyeing plants produce large amounts of high chroma wastewater during the production process (Xu et al. 2015b). Many aromatic agents, metals and chlorides contained in wastewater are toxic to aquatic organisms, human beings and even affect biosphere (Laszlo \& Erzsebet 2008). Every year, $12 \%$ of synthetic dyes are run off during the production process, resulting in dye-containing wastewater with high chroma and chemical oxygen demand (COD), low biochemical oxygen demand, oxidation resistance and difficult biodegradation (Xu et al. 2016). Therefore, the most critical problem in the dyeing industry is how to treat visible pollutants contained in dye wastewater (Lee et al. 2006) to meet the industry emission standards.

Advanced oxidation processes (AOPs) have great potential for degrading organic pollutants in industrial wastewater. This oxidation mechanism produces strong oxidants, such as hydroxyl radicals (Cheng et al. 2016), which have high activity and are non-selective for decomposing organic pollutants into $\mathrm{CO}_{2}, \mathrm{H}_{2} \mathrm{O}$, and inorganic salts in the water environment (Inmaculada et al. 2015). Fenton oxidation $\left(\mathrm{Fe}^{2+} / \mathrm{H}_{2} \mathrm{O}_{2} / \mathrm{H}^{+}\right.$) has received the intensive attention in wastewater treatment due to its superior degradation efficiency, rapid reaction speed and moderate investment (Azizi et al. 2015). Under weak acidic conditions, $\mathrm{Fe}^{2+}$ is oxidized by $\mathrm{H}_{2} \mathrm{O}_{2}$ to form $\mathrm{Fe}^{3+}$, hydroxyl $(\cdot \mathrm{OH})$ and $\mathrm{OH}^{-}(\mathrm{Xu}$ et al. 2015a), which produces highly reactive $\cdot \mathrm{OH}$ to destroy the molecular structure of organic dyes, thus achieves the decolourization effect of dye wastewater. The spectrophotometer can record the mass concentration change of the dye (Gao et al. 2019a, Gao et al. 2019b, Sibel et al. 2012, Xu et al. 2018) and monitor the instantaneous state of the dye decolourization during the Fenton oxidation process. Therefore, the experimental results are real-time and reliable with a very minor error.

In the present study, azo dye Acid Light Yellow 2G was selected as the target pollutant. We studied the effect of initial $\mathrm{Fe}^{2+}$, initial $\mathrm{H}_{2} \mathrm{O}_{2}$ concentration, initial $\mathrm{pH}$ value of the solution and different dye concentrations on the degradation of ALY $2 \mathrm{G}$ by the Fenton method. The decolourization kinetics performance of Fenton oxidation was studied based on the experimental data. The kinetic model of azo dye degradation with Fenton's reagent was established. In this study, the online spectrophotometric system was used to monitor the degradation of Acid Light Yellow 2G. The kinetic analysis 


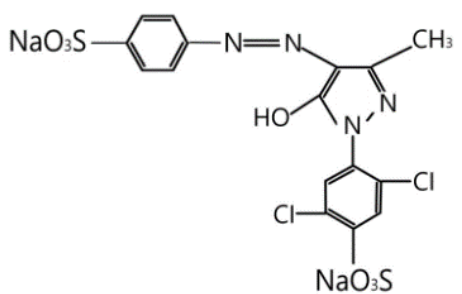

Fig. 1: Molecular structure of Acid Light Yellow 2G.

result was expected to provide basic experimental data for a deeper understanding of the Fenton oxidation process of wastewater containing ALY $2 \mathrm{G}$ dye.

\section{MATERIALS AND METHODS}

\section{Chemical Reagents}

The structure of Acid Light Yellow 2G is shown in Fig. 1. ALY $2 \mathrm{G}$ was purchased from Shijiazhuang Dyestuffs Company (China) and the ALY 2G solution was prepared by dissolving a requisite quantity of dye in ultrapure water. Ferrous sulphate $\left(\mathrm{FeSO}_{4} \cdot 7 \mathrm{H}_{2} \mathrm{O}\right)$ and hydrogen peroxide $\left(\mathrm{H}_{2} \mathrm{O}_{2}\right)$ were purchased from Tianjin Damao Chemical Reagent Company, and sulfuric $\operatorname{acid}\left(\mathrm{H}_{2} \mathrm{SO}_{4}\right)$ from Modern Chemical Reagent Company. They were of reagent analytical grade.

\section{Apparatus Set-up}

The online spectrophotometric system is shown in Fig. 2. Reaction section (degradation device) includes a digital magnetic stirrer apparatus (Shanghai Instrument Company, China), and a $500 \mathrm{~mL}$ beaker. Optical measuring part contains UV-Vis spectrometer (UNICO 2802, Shanghai, China), cycle peristaltic pump and cuvette $(1 \mathrm{~mL})$. The recording unit is a computer with the monitoring frequency of $12 \mathrm{~min}^{-1}$ during the oxidation process.

\section{Experimental Procedure}

Fenton oxidation process was performed in a $500 \mathrm{~mL}$ vessel. With the role of a peristaltic pump, the simulated

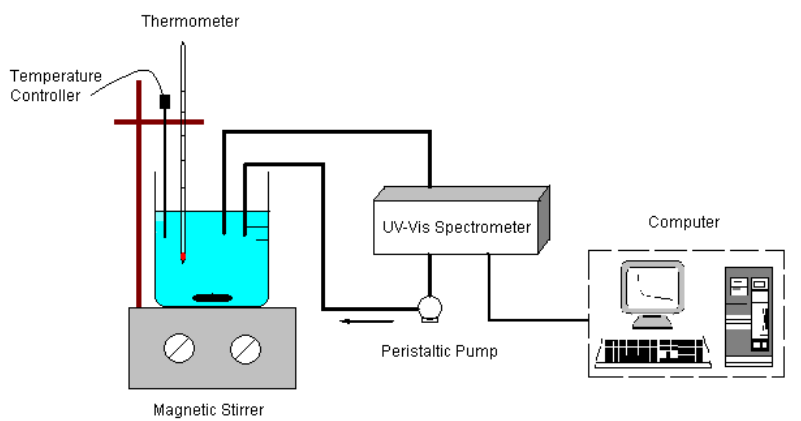

Fig. 2: Online spectrophotometric system. dye wastewater was pumped into the cuvette of UV-Vis spectrophotometer. Absorbance at maximal absorption peak of dye was obtained by the spectrophotometer. The effects of $\mathrm{FeSO}_{4}$ dosage, $\mathrm{H}_{2} \mathrm{O}_{2}$ dosage, initial $\mathrm{pH}$, and initial dye concentration on the degradation of Acid Light Yellow 2G were studied by single-factor experiments.

\section{Feasibility Analysis of Online Spectrophotometric Technique}

Online spectrophotometry method was applied to analyze the decolourization of ALY $2 \mathrm{G}$ dye in the Fenton process. The UV-Vis spectra of ALY $2 \mathrm{G}, \mathrm{H}_{2} \mathrm{SO}_{4}, \mathrm{Fe}^{2+}$, and $\mathrm{Fe}^{3+}$ are presented in Fig. 3. Azo dye ALY $2 \mathrm{G}$ has a maximum adsorption peak of $402 \mathrm{~nm}$, which does not vary with the addition of $\mathrm{H}_{2} \mathrm{SO}_{4}, \mathrm{Fe}^{2+}$ and $\mathrm{Fe}^{3+}$. Therefore, during the experiment, online spectrophotometry can be used to monitor ALY $2 \mathrm{G}$ wavelength at $402 \mathrm{~nm}$. The standard equations and standard curves for dye concentration (C) and absorbance (A) are given in Fig. 4. The relationship of the absorbance (A) at $402 \mathrm{~nm}$ against concentration (C) of ALY 2G is A = $0.0309 \mathrm{C}+0.0015\left(\mathrm{R}^{2}=0.9998\right)$.

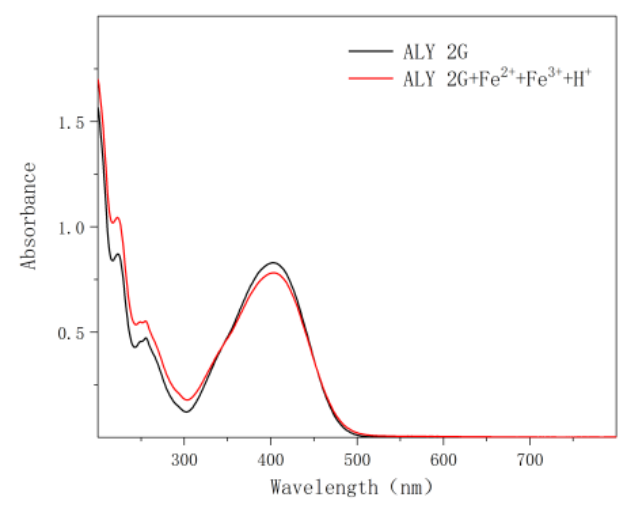

Fig. 3: Comparison of dye UV-Vis spectra between dye and dye $\left(+\mathrm{H}_{2} \mathrm{SO}_{4}+\mathrm{Fe}^{2+}+\mathrm{Fe}^{3+}\right)$.

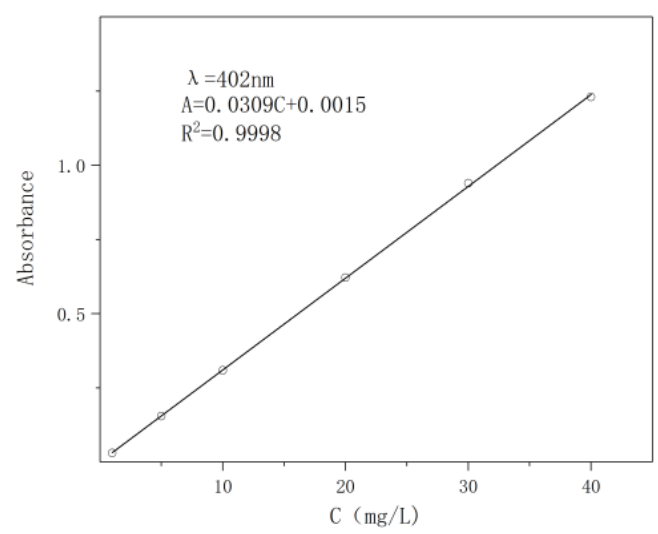

Fig. 4: Standard curve. 


\section{RESULTS AND DISCUSSION}

\section{Single Factor Experiment}

The effects of initial $\mathrm{FeSO}_{4}$ dosage, initial $\mathrm{H}_{2} \mathrm{O}_{2}$ dosage, $\mathrm{pH}$ value, and initial dye concentration on chroma removal have been discussed. When the reaction time reaches 300 $\mathrm{s}$, the decolourization rate of the dye was calculated. The colour removal rate $(\mathrm{R})$ is defined as given in Eqs. $1 . \mathrm{C}_{0}$ and $\mathrm{C}$ represent the initial and the instant concentrations of the dye with reaction time, respectively.

$$
R=\frac{C_{0}-C}{C_{0}} \times 100 \%
$$

The effect of $\mathrm{FeSO}_{4}$ dosage: The effect of different dosages of $\mathrm{Fe}^{2+}$ on the dye decolourization rate is shown in Fig. 5. Under the dye concentration of $20 \mathrm{mg} / \mathrm{L}, \mathrm{H}_{2} \mathrm{O}_{2}$ dosage of 0.6 $\mathrm{mmol} / \mathrm{L}$ and $\mathrm{pH}$ of 3 conditions, $\mathrm{Fe}^{2+}$ concentration ranged from 0.04 to $0.4 \mathrm{mmol} / \mathrm{L}$ (temperature kept at $25^{\circ} \mathrm{C}$ ). It can be observed from Fig. 5 that different concentrations of $\mathrm{Fe}^{2+}$ have a great effect on colour removal. When the $\mathrm{Fe}^{2+}$ concentration is $0.04-0.1 \mathrm{mmol} / \mathrm{L}$, the colour removal rate becomes higher and higher as $\mathrm{Fe}^{2+}$ concentration increases. The colour removal rate was $93.46 \%$ when $\mathrm{Fe}^{2+}$ concentration was $0.1 \mathrm{mmol} / \mathrm{L}$. In addition, the colour removal rate of ALY 2G increased sharply in the first $30 \mathrm{~s}$ stage with the increase of $\mathrm{Fe}^{2+}$ concentration. After 30 seconds, the colour removal rate of ALY $2 \mathrm{G}$ dye did not increase, but the decolourization rate decreased slightly when the concentration ranges of dye changed from 0.2 to $0.4 \mathrm{mmol} / \mathrm{L}$. This experimental result makes us known that excessive $\mathrm{Fe}^{2+}$ concentration is not beneficial to decolourization of ALY 2G among Fenton oxidation process. This reason is that because the excess ferrous ion competes with the dye molecules for the hydroxyl radical $\cdot \mathrm{OH}\left(\mathrm{Fe}^{2+}+\cdot \mathrm{OH} \rightarrow \mathrm{Fe}^{3+}+\mathrm{OH}^{-}\right)(\mathrm{Xu}$ et al. 2015b). Therefore, choosing an appropriate amount of $\mathrm{Fe}^{2+}$ can improve the degradation effect of the ALY $2 \mathrm{G}$ dye. We have chosen the initial $\mathrm{Fe}^{2+}$ concentration of $0.1 \mathrm{mmol} / \mathrm{L}$

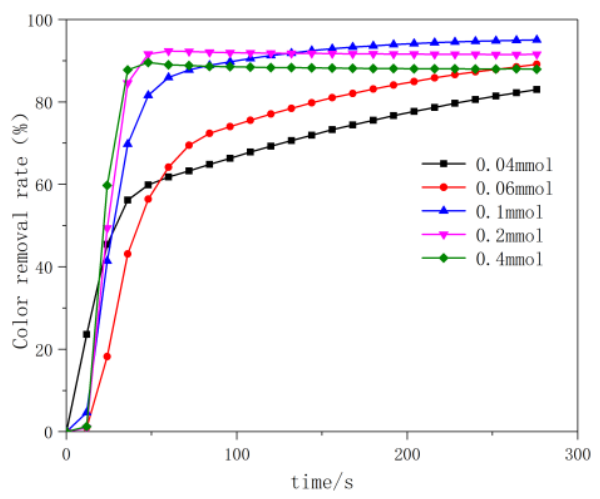

Fig. 5: Influence of initial $\mathrm{Fe}^{2+}$ concentration on dye removal. as an optimum dosage for efficient decolourization to ALY $2 \mathrm{G}$ aqueous solutions.

The effect of initial $\mathrm{H}_{2} \mathrm{O}_{2}$ dosage: $\mathrm{H}_{2} \mathrm{O}_{2}$ is one of the very important factors affecting the degradation efficiency of dyes. The hydroxyl group can decompose the molecular structure of azo dyes, and then bleach ALY $2 \mathrm{G}$ dye wastewater. The hydroxyl group derives from $\mathrm{H}_{2} \mathrm{O}_{2}$. Fig. 6 displays the effect of the decolourization rate R of ALY $2 \mathrm{G}$ on various $\mathrm{H}_{2} \mathrm{O}_{2}$ concentrations. We can see from Fig. 6 that experimental monitoring in $300 \mathrm{~s}$, the decolourization trends of ALY $2 \mathrm{G}$ under $0.6,3$ and $6 \mathrm{mmol} / \mathrm{L}$ concentrations are very similar. The decolourization rate was $84.53 \%$ (lowest value) when $\mathrm{H}_{2} \mathrm{O}_{2}$ concentration was $0.18 \mathrm{mmol} / \mathrm{L}$. When the $\mathrm{H}_{2} \mathrm{O}_{2}$ concentration was increased to $0.6 \mathrm{mmol} / \mathrm{L}$, the dye decolourization rate reached $93.38 \%$. However, when the $\mathrm{H}_{2} \mathrm{O}_{2}$ concentration was $12 \mathrm{mmol} / \mathrm{L}$, the decolourization rate was relatively low $(90.52 \%)$. The reason is that excess $\mathrm{H}_{2} \mathrm{O}_{2}$ will consume $\cdot \mathrm{OH}$ and compete with ALY $2 \mathrm{G}$ dye for hydroxyl radical $\cdot \mathrm{OH}$ (Eqs. 2-3). This process results in the production of the hydroperoxyl radical $(\cdot \mathrm{OOH}$ as a scavenger of hydroxyl radical) and then decreases the colour removal rate of dye (Sehested et al. 2003, Xu et al. 2016). In brief, we choose $0.6 \mathrm{mmol} / \mathrm{L}$ as an optimum $\mathrm{H}_{2} \mathrm{O}_{2}$ concentration of the decolourization of ALY $2 \mathrm{G}$ in the Fenton oxidation process.

$$
\begin{aligned}
& \mathrm{H}_{2} \mathrm{O}_{2}+\cdot \mathrm{OH} \rightarrow \cdot \mathrm{OOH}+\mathrm{H}_{2} \mathrm{O} \\
& \cdot \mathrm{OH}+\cdot \mathrm{OOH} \rightarrow \mathrm{H}_{2} \mathrm{O}+\mathrm{O}_{2}
\end{aligned}
$$

The effect of solution $\mathrm{pH}$ : The $\mathrm{pH}$ of the solution plays an important role in dye degradation for the Fenton process. The influence of $\mathrm{pH}$ value on the decomposition of ALY $2 \mathrm{G}$ is illustrated in Fig. 7. The change trends of decolourization rate with various $\mathrm{pH}$ value are consistent. The decolourization rate increases from $57.12 \%$ to $94.66 \%$ as the $\mathrm{pH}$ value increases from 1.5 to 3 . However, when the $\mathrm{pH}$ value further increases to 4 , the decolourization rate decreases to be $89.39 \%$. At the lower $\mathrm{pH}$ value $(<3)$ the $\cdot \mathrm{OH}$ is consumed by the excessive hydrogen ion $\left(\cdot \mathrm{OH}+\mathrm{H}^{+}+\mathrm{e}^{-} \rightarrow \mathrm{H}_{2} \mathrm{O}\right)$, and

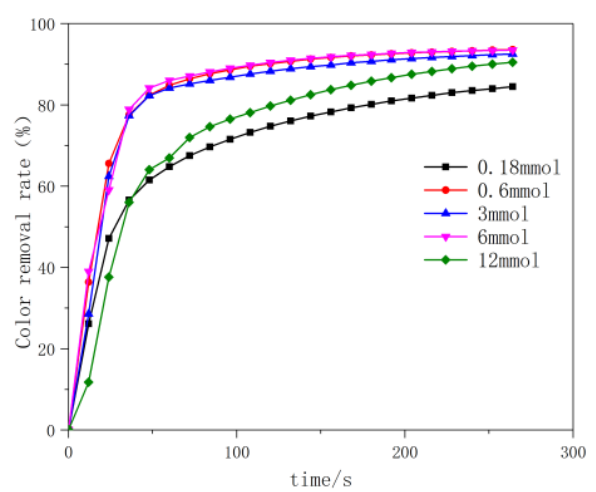

Fig. 6: Influence of initial $\mathrm{H}_{2} \mathrm{O}_{2}$ concentration on dye removal. 


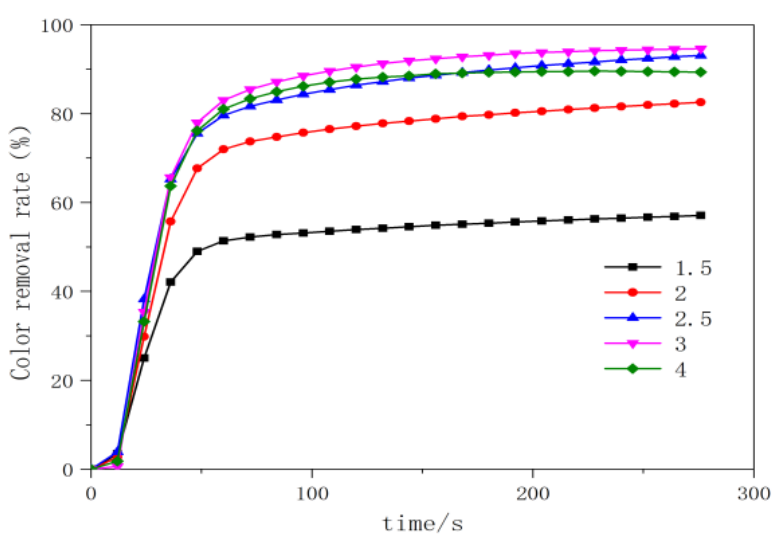

Fig. 7: Influence of initial $\mathrm{pH}$ on dye removal.

thus the decolourization rate is relatively small. When the solution $(\mathrm{pH}>3)$, with the formation of the iron hydroxide complex, the hydrogen peroxide is decomposed and the ferrous ion catalyst is invalidated, which ultimately leads to a reduction in the oxidation ability of Fenton (Gao et al. 2014). Therefore, the $\mathrm{pH}$ value of 3 is considered to be the optimum value for the decolourization of azo dye ALY 2G in Fenton oxidation.

The effect of initial ALY 2 G concentration: Fig. 8 shows the trend of the colour removal rate with various dye concentrations (conditions: $\left[\mathrm{Fe}^{2+}\right]=0.1 \mathrm{mmol} / \mathrm{L},\left[\mathrm{H}_{2} \mathrm{O}_{2}\right]=$ $0.6 \mathrm{mmol} / \mathrm{L}$, and $\mathrm{pH}=3$ ). Although the initial concentrations of the dye ALY $2 \mathrm{G}$ were different (from 10 to $40 \mathrm{mg} / \mathrm{L}$ ), the chroma removal rate of dye can all reach more than $90 \%$ and the difference of all removal rates is very small after 300s. Moreover, it can be seen that the reaction rate gradually decreases as increasing dye concentration between 50s and $150 \mathrm{~s}$. The reason for this is that as the initial concentration of the Acid Light Yellow 2G dye solution increases, the number of dye molecules in the solution increases, whereas the amount of $\cdot \mathrm{OH}$ in the solution does not increase, which leads to a decrease in the reaction rate.

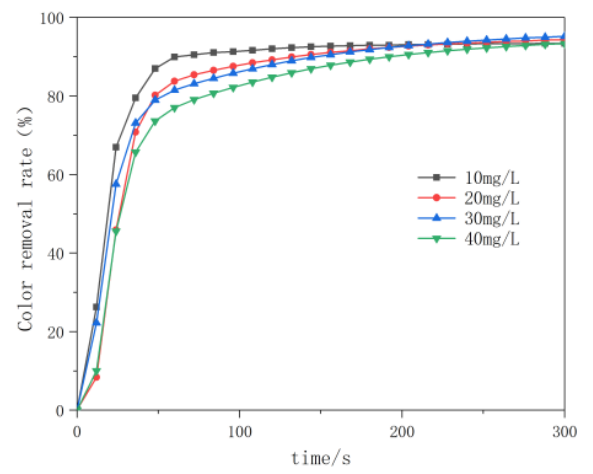

Fig. 8: Influence of initial dye concentration on dye removal.

\section{Reaction Kinetic Fitting Analysis}

Kinetic process analysis is helpful to understand the Fenton oxidation process. Acid Light Yellow $2 \mathrm{G}$ was decolourized successfully in the experimental process, and the first stage of decolourization was analysed by first-order kinetics (Gao et al. 2019b). The first-order kinetics calculation formula (Eqs. 4-5) is as follow:

$$
\begin{aligned}
& \frac{\mathrm{dC}}{\mathrm{dt}}=K_{a p} t \\
& \ln \frac{C_{0}}{C_{t}}=K_{a p} t
\end{aligned}
$$

Where, $t$ is the reaction time; $C$ is the instant dye concentration; $C_{0}$ represents the initial dye concentration.

Figs. 9-12 show the changes of $\ln \left(\mathrm{C}_{0} / \mathrm{C}_{\mathrm{t}}\right)$ with time under different initial $\mathrm{Fe}^{2+}$ concentrations, different $\mathrm{H}_{2} \mathrm{O}_{2}$ concentrations, different $\mathrm{pH}$, and different dye concentrations, respectively. The linear fitting results of the relationship curve between $\ln \left(\mathrm{C}_{0} / \mathrm{C}_{\mathrm{t}}\right)$ and time $(\mathrm{t})$ are given in Table 1. The kinetic parameters are also listed in Table 1. The values of the kinetic parameters (the correlation coefficients $\mathrm{R}^{2}$ ) are all above 0.94 . It can be seen that the oxidation

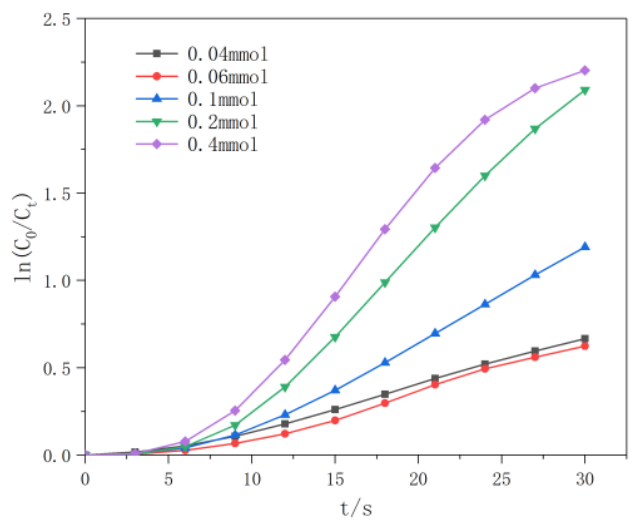

Fig. 9: First-order kinetics of reactions in different $\mathrm{Fe}^{2+}$ concentrations.

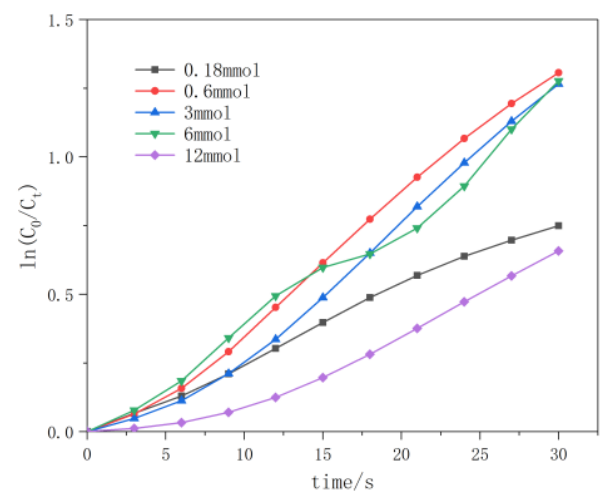

Fig. 10: First-order kinetics of reactions in different $\mathrm{H}_{2} \mathrm{O}_{2}$ concentrations. 


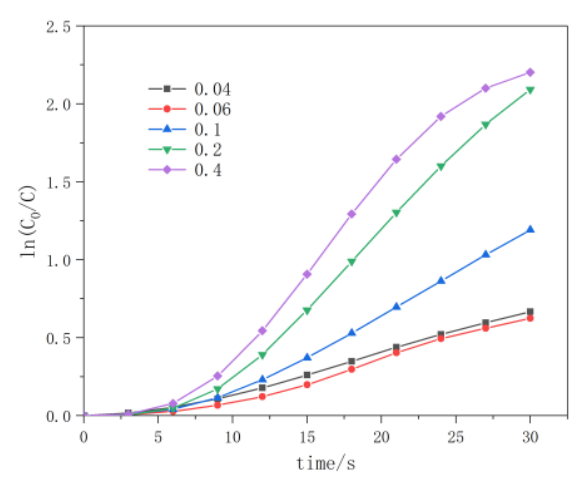

Fig. 11: First-order kinetics of reactions in different $\mathrm{pH}$.

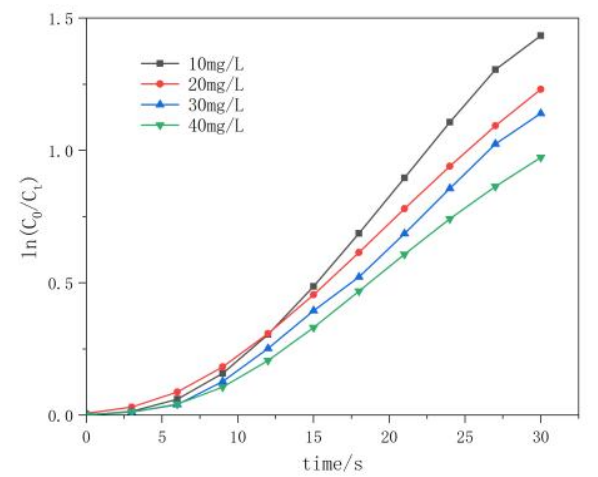

Fig. 12: First-order kinetics of reactions in different dye concentrations.

process of Acid Light Yellow 2G by Fenton method accords with first-order kinetics.

First-order kinetics fitting is performed for the fast reaction stage. The fast stage of the Fenton oxidation process abides by first-order kinetics. Under the optimal reaction condition in Fenton oxidation, the correlation coefficient is 0.98 and the reaction rate $\mathrm{K}_{\mathrm{ap}}$ is $0.04824 \mathrm{~s}^{-1}$.

\section{Kinetics Study}

The Fenton oxidation method uses a catalyst $\mathrm{Fe}^{2+}$ and $\mathrm{H}_{2} \mathrm{O}_{2}$ to undergo a redox reaction to form a highly active $\cdot \mathrm{OH}$ which can decompose the molecular structure of organic dyes. The reaction mechanism can be expressed by (Eqs. 6-14) (D represents dye molecules) (Gao et al. 2014, Gao et al. 2019b, Kuši et al. 2006, Sibel et al. 2012, Sehested et al. 2003).

$$
\begin{gathered}
\mathrm{Fe}^{2+}+\mathrm{H}_{2} \mathrm{O}_{2} \rightarrow \mathrm{Fe}^{3+}+\cdot \mathrm{OH}+\mathrm{OH}^{-} \\
k_{1}=76 \mathrm{M}^{-1} \mathrm{~s}^{-1} \\
\mathrm{D}+\cdot \mathrm{OH} \rightarrow D_{\text {oxid }} \\
\mathrm{Fe}^{2+}+\cdot \mathrm{OH} \rightarrow \mathrm{Fe}^{3+}+\mathrm{OH}^{-} \\
k_{3}=3.2 \times 10^{8} \\
\mathrm{H}_{2} \mathrm{O}_{2}+\cdot \mathrm{OH} \rightarrow \cdot \mathrm{OOH}+\mathrm{H}_{2} \mathrm{O}
\end{gathered}
$$

$$
\begin{gathered}
k_{4}=4.5 \times 10^{7} \\
\cdot \mathrm{OH}+\cdot \mathrm{OOH} \rightarrow \mathrm{H}_{2} \mathrm{O}+\mathrm{O}_{2} \\
k_{5}=6.6 \times 10^{11} \\
\mathrm{Fe}^{3+}+\mathrm{H}_{2} \mathrm{O}_{2} \rightarrow \mathrm{Fe}^{2+}+\mathrm{H}^{+}+\cdot \mathrm{OOH} \\
k_{6}=0.02 \mathrm{M}^{-1} \mathrm{~S}^{-1}
\end{gathered}
$$

The reaction rate of dye can be defined as:

$$
-\frac{\mathrm{d}[\mathrm{D}]}{\mathrm{dt}}=k_{2}[\cdot O H][D]
$$

According to the steady-state assumption, $[\cdot \mathrm{OH}]$ can be obtained as follow:

$$
\begin{gathered}
\frac{\mathrm{d}[\cdot \mathrm{OH}]}{\mathrm{dt}}=k_{1}\left[\mathrm{Fe}^{2+}\right]\left[\mathrm{H}_{2} \mathrm{O}_{2}\right]-k_{2}[\cdot \mathrm{OH}][\mathrm{D}]-k_{3}\left[\mathrm{Fe}^{2+}\right][\cdot \mathrm{OH}] \\
\quad-k_{4}\left[\mathrm{H}_{2} \mathrm{O}_{2}\right][\cdot \mathrm{OH}]-k_{5}[\cdot \mathrm{OH}][\cdot \mathrm{OOH}]=0 \\
-\frac{\mathrm{d}[\cdot \mathrm{OOH}]}{\mathrm{dt}}=k_{4}\left[\mathrm{H}_{2} \mathrm{O}_{2}\right][\cdot \mathrm{OH}]-k_{5}[\cdot \mathrm{OOH}][\cdot \mathrm{OH}]=0 .
\end{gathered}
$$

According to Eq. (14), we obtain:

$$
k_{5}[\cdot \mathrm{OH}][\cdot \mathrm{OOH}]=k_{4}\left[\mathrm{H}_{2} \mathrm{O}_{2}\right][\cdot \mathrm{OH}]
$$

According to Eqs. (13) and (15), we obtain:

$$
\begin{gathered}
\frac{\mathrm{d}[\cdot \mathrm{OH}]}{\mathrm{dt}}=k_{1}\left[\mathrm{Fe}^{2+}\right]\left[\mathrm{H}_{2} \mathrm{O}_{2}\right]-k_{2}[\cdot \mathrm{OH}][\mathrm{D}]-k_{3}\left[\mathrm{Fe}^{2+}\right][\cdot \mathrm{OH}] \\
-2 k_{4}\left[\mathrm{H}_{2} \mathrm{O}_{2}\right][\cdot \mathrm{OH}]=0 \\
{[\cdot \mathrm{OH}]=\frac{k_{1}\left[\mathrm{Fe}^{2+}\right]\left[\mathrm{H}_{2} \mathrm{O}_{2}\right]}{k_{2}[\mathrm{D}]+k_{3}\left[\mathrm{Fe}^{2+}\right]+2 k_{4}\left[\mathrm{H}_{2} \mathrm{O}_{2}\right]}}
\end{gathered}
$$

Combined Eqs. (12) with (17), we obtained:

$$
-\frac{\mathrm{d}[\mathrm{D}]}{\mathrm{dt}}=\frac{k_{1} k_{2}\left[\mathrm{Fe}^{2+}\right]\left[\mathrm{H}_{2} \mathrm{O}_{2}\right][\mathrm{D}]}{k_{2}[D]+k_{3}\left[\mathrm{Fe}^{2+}\right]+2 k_{4}\left[\mathrm{H}_{2} \mathrm{O}_{2}\right]}
$$

Thus, Eq. (18) deduces to

$$
\frac{\left[\mathrm{H}_{2} \mathrm{O}_{2}\right][\mathrm{D}]}{-\frac{d[D]}{d t}}=\frac{[D]}{k_{1}\left[\mathrm{Fe}^{2+}\right]}+\frac{k_{3}}{k_{1} k_{2}}+\frac{2 k_{4}\left[\mathrm{H}_{2} \mathrm{O}_{2}\right]}{k_{2} k_{1}\left[\mathrm{Fe}^{2+}\right]}
$$

By fitting the first-order kinetics to the oxidation reaction process in the last stage, the results show that the correlation coefficients are all above 0.95 . It can be seen that the fast stage meets the first-order kinetics, so that:

$$
-\frac{\mathrm{d}[\mathrm{D}]}{\mathrm{dt}}=\operatorname{Kap}[D]
$$

Combined Eqs. (19) with (20), we obtained:

$$
\begin{gathered}
\frac{\left[\mathrm{H}_{2} \mathrm{O}_{2}\right]}{\text { Kap }}=\mathrm{k}[D]_{0}+B \\
\mathrm{~B}=\frac{k_{3}}{k_{2} k_{1}}+\frac{2 k_{4}\left[\mathrm{H}_{2} \mathrm{O}_{2}\right]_{0}}{k_{2} k_{1}\left[\mathrm{Fe}^{2+}\right]_{0}}
\end{gathered}
$$

The experimental results are shown in Fig. 13. $\left[\mathrm{H}_{2} \mathrm{O}_{2}\right] / \mathrm{K}_{\mathrm{ap}}$ has a good linear relationship with the dye concentration $\left(\mathrm{R}^{2}\right.$ 
Table 1: Degradation kinetics data.

\begin{tabular}{|c|c|c|c|c|c|}
\hline \multirow[t]{2}{*}{$\mathrm{FeSO}_{4}(\mathrm{mmol} / \mathrm{L})$} & \multirow[t]{2}{*}{$\mathrm{H}_{2} \mathrm{O}_{2}(\mathrm{mmol} / \mathrm{L})$} & \multirow[t]{2}{*}{$\mathrm{pH}$} & \multirow[t]{2}{*}{ Dye concentration $(\mathrm{mg} / \mathrm{L})$} & \multicolumn{2}{|c|}{ First-order kinetics } \\
\hline & & & & $\mathrm{K}_{\mathrm{ap}}$ & $\mathrm{R}^{2}$ \\
\hline 0.04 & 3 & 3 & 20 & 0.0239 & 0.98182 \\
\hline 0.06 & 3 & 3 & 20 & 0.02298 & 0.95885 \\
\hline 0.1 & 3 & 3 & 20 & 0.04236 & 0.95748 \\
\hline 0.2 & 3 & 3 & 20 & 0.07708 & 0.95702 \\
\hline 0.4 & 3 & 3 & 20 & 0.08617 & 0.96601 \\
\hline 0.1 & 0.18 & 3 & 20 & 0.02634 & 0.99524 \\
\hline 0.1 & 0.6 & 3 & 20 & 0.04658 & 0.99384 \\
\hline 0.1 & 3 & 3 & 20 & 0.0448 & 0.98128 \\
\hline 0.1 & 6 & 3 & 20 & 0.04107 & 0.98546 \\
\hline 0.1 & 12 & 3 & 20 & 0.023 & 0.95326 \\
\hline 0.1 & 0.6 & 1.5 & 20 & 0.02147 & 0.99136 \\
\hline 0.1 & 0.6 & 2 & 20 & 0.03481 & 0.99652 \\
\hline 0.1 & 0.6 & 2.5 & 20 & 0.0447 & 0.99558 \\
\hline 0.1 & 0.6 & 3 & 20 & 0.04824 & 0.98836 \\
\hline 0.1 & 0.6 & 4 & 20 & 0.04468 & 0.99148 \\
\hline 0.1 & 0.6 & 3 & 10 & 0.05251 & 0.96378 \\
\hline 0.1 & 0.6 & 3 & 20 & 0.03869 & 0.94459 \\
\hline 0.1 & 0.6 & 3 & 30 & 0.04116 & 0.96418 \\
\hline 0.1 & 0.6 & 3 & 40 & 0.03526 & 0.96477 \\
\hline
\end{tabular}

$=0.97133$ ). According to intercept $\mathrm{B}$, the intrinsic reaction rate constant of the dye concentration and $\cdot \mathrm{OH}$ in the aqueous solution is obtained $\left(k_{2}=0.55 \times 10^{9} M^{-1} S^{-1}\right)$.

\section{CONCLUSION}

In this study, the degradation of the azo dye Acid Light Yellow $2 \mathrm{G}$ by Fenton method and its influence factors (initial dye concentration, initial solution $\mathrm{Fe}^{2+}$ concentration, initial $\mathrm{H}_{2} \mathrm{O}_{2}$ concentration, and initial $\mathrm{pH}$ value) were studied. The following conclusions can be made.

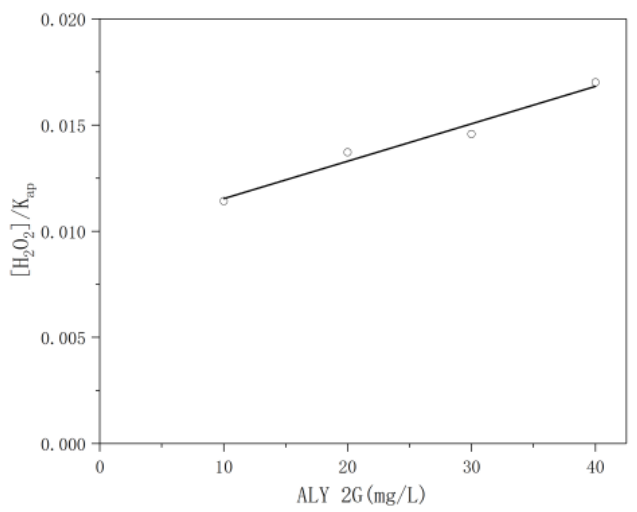

Fig. 13: Relationship between $\left[\mathrm{H}_{2} \mathrm{O}_{2}\right] / \mathrm{K}_{\mathrm{ap}}$ and $[\mathrm{D}]_{0}$.
1. The online spectrophotometric method was used to monitor the absorbance of dye Acid Light Yellow 2G with Fenton oxidation. This technique is accurate, feasible and fast. The Fenton oxidation process can be divided into two stages: a rapid degradation stage $(\mathrm{t}<30 \mathrm{~s})$ and a slow degradation phase $(\mathrm{t}>30 \mathrm{~s})$.

2. The best experimental conditions for degradation of dyes are that $\mathrm{FeSO}_{4}$ is $0.1 \mathrm{mmol} / \mathrm{L}, \mathrm{H}_{2} \mathrm{O}_{2}$ is $0.6 \mathrm{mmol} / \mathrm{L}$, initial $\mathrm{pH}$ is 3 , and when the dye concentration is $20 \mathrm{mg} / \mathrm{L}$, the colour removal rate is $94.66 \%$. Fenton oxidation process conforms to first-order reaction kinetics in the first stage. According to the formula $\mathrm{K}_{\mathrm{ap}}=\ln \left(\mathrm{C}_{0} / \mathrm{C}_{\mathrm{t}}\right)$, the first-order rate constant is the linear fitting slope. The reaction rate constant $\mathrm{K}_{\mathrm{ap}}$ is $0.04824 \mathrm{~s}^{-1}$ under the best experimental conditions.

3. During the Fenton oxidation process, the intrinsic reaction rate constant of the ALY $2 \mathrm{G}$ dye and $\cdot \mathrm{OH}$ in aqueous solution was $\left(k_{2}=0.55 \times 10^{9} M^{-1} S^{-1}\right)$.

\section{ACKNOWLEDGEMENTS}

The work is partly supported by the Scientific Pre-Research Fund of Hebei GEO University in 2015(YK201501), the Young Talent Plan of Hebei Province 2016, and the Excellent Youth Foundation of Hebei Province Department of Education of China (Grant No. Y2011110) 


\section{REFERENCES}

Azizi, A., Moghaddam, M. R. A., Maknoon, R. and Kowsari, E. 2015. Comparison of three combined sequencing batch reactor followed by enhanced Fenton process for an azo dye degradation: Biodecolorization kinetics study. Journal of Hazardous Materials, 299: 343-350.

Cheng, M., Zeng, G. M., Huang, D., Lai, C., Xu, P., Zhang, C. and Liu, Y. 2016. Hydroxyl radicals based advanced oxidation processes (AOPs) for remediation of soils contaminated with organic compounds: a review. Chemical Engineering Journal, 284: 582-598.

Gao, A. F., Wang, W. P., Li, A. G. and Jiao, Z. 2014. Kinetics of reactive dark blue B-2GLN with Fenton oxidation process. Chinese Journal of Environmental Engineering, 8(6): 2407-2412.

Gao, A. F., Li, A. G., Gao, Z. J., Peng, Z. X. and Wang, W. P. 2019a. Study of decolorization kinetics of reactive red B-2BF in Fenton oxidation process. Fresenius Environmental Bulletin, 28(9): 6435-6443.

Gao, A. F., Li, A. G. and Wang, W. P. 2019b. Degradation kinetics of Reactive Dark Blue B-2GLN with Fenton oxidation process. Desalination and Water Treatment, 141: 301-309.

Inmaculada, O., Anuska, M.C., Juan, M. L. and Santiago, E. 2015. Advanced technologies for water treatment and reuse. Aiche Journal, 61(10): 3146-3158.

Kuši , H., Koprivanac, N., Boži , A. L. and Selanec, I. 2006. Photo-assisted Fenton type processes for the degradation of phenol: A kinetic study. Journal of Hazardous Materials, 136(3): 632-644.

Laszlo, W. and Erzsebet, T. 2008. Irradiation treatment of azo dye containing wastewater: An overview. Radiation Physics and Chemistry, 77(3): 225-244.

Lee, J. W., Choi, S. P., Thiruvenkatachari, R., Shim, W. G. and Moon, H. 2006. Submerged microfiltration membrane coupled with alum coagulation/powdered activated carbon adsorption for complete decolorization of reactive dyes. Water Research, 40(3): 435-444.

Sibel, T., Tülin, G. and Osman, D. 2012. On-line spectrophotometric method for the determination of optimum operation parameters on the decolorization of Acid Red 66 and Direct Blue 71 from aqueous solution by Fenton process. Chemical Engineering Journal, 181: 431-442.

Sehested, K., Bjergbakke, E. and Rasmussen, O. L. 2003. Reactions of $\mathrm{H}_{2} \mathrm{O}_{3}$ in the pulse-irradiated $\mathrm{Fe}(\mathrm{II})-\mathrm{O}_{2}$ system. The Journal of Chemical Physics, 51(8): 3159-3166.

Xu, H., Li, M., Wu, F. M. and Zhang, J. 2015a. Optimization of Fenton oxidation process for treatment of hexogeon industrial wastewater using response surface methodology. Desalination and Water Treatment, 55: $77-85$.

Xu, H., Yu, T. L., Wang, J. X. and Li, M. 2015b. Online monitoring of Fenton-mediated Reactive Red 6B oxidation kinetics. Environmental Progress \& Sustainable Energy, 34: 1019-1027.

Xu, H., Yu, T. L., Guo, X. X. and Wang, J. X. 2016. $\mathrm{Fe}^{3+} / \mathrm{H}_{2} \mathrm{O}_{2}$ Fenton degradation of wastewater containing dye under UV irradiation. Desalination and Water Treatment, 57: 18028-18037.

Xu, H., Zhang, D. D., Yu, T. L., Wu, F. M. and Li, H. 2018. Studying Fenton oxidation kinetics of mixed dyes wastewater and salt effect by online spectrophotometry. Desalination and Water Treatment, 102: 340-348. 